\title{
HIP JOINT ARTHROSCOPY IN PROFESSIONALLY ACTIVE PATIENTS WITH OSTEOARTHRITIS
}

\section{MAREK DROBNIEWSKI ${ }^{1}$, MAREK SYNDER ${ }^{1}$, MICHAŁ SKRZYPEK ${ }^{1}$, KAJETAN PSTRĄGOWSKI ${ }^{1}$, MICHAŁ POLGUJ ${ }^{2}$, and ANDRZEJ BOROWSKI ${ }^{1}$}

\author{
Medical University of Lodz, Łódź, Poland \\ ${ }^{1}$ Orthopedics and Pediatrics Orthopedics Department \\ ${ }^{2}$ Department of Angiology, Interfaculty Chair of Anatomy and Histology
}

\begin{abstract}
Objectives: The primary endpoints of the study were to assess the effectiveness of hip joint arthroscopy in the treatment of femoroacetabular impingement (FAI) in patients with joint gap stenosis and to determine if and how quickly patients were able to return to work and physical activity. Material and Methods: The prospective study of patients undergoing hip joint arthroscopy due to pain in FAI has been conducted. They were divided into 2 groups depending on the degree of the radiological examination. The criterion was the width of the joint gap. The study group involved 47 patients with hip joint gap of 2-3 mm, identified by means of the standardized X-ray examination. The control group consisted of 45 patients with hip joint gap $>3 \mathrm{~mm}$. The post-operative follow-up period of the patients lasted at least 2 years. In addition, the Western Ontario McMaster Universities Osteoarthritis Index (WOMAC) questionnaire together with Harris Hip Score (HHS) were applied. The patients were also evaluated for the post-operative time period enabling return to work. Results: All the patients after hip joint arthroscopy returned to normal physical activity within 12 weeks after operation, enabling their return to work. However, it should be noted that during the post-operative follow-up, pain sensations either recurred or did not regress in 37 patients in the study group and 12 patients in the control group after treatment. The nearly equal results of the WOMAC questionnaire and HHS before operation significantly vary between both groups in the last follow up. In the study group they did not change expressively. Conclusions: Despite the little invasiveness, hip joint arthroscopy in patients with joint gap stenosis brings about the far from satisfactory results. This procedure is not worth considering. Despite unsatisfactory pain relief, patients decided to returned to work, due to their occupational position and for fear of losing the job due to long absenteeism. Int J Occup Med Environ Health. 2019;32(1):115-20
\end{abstract}

Key words:

degenerative disease, return to work, arthroscopy, hip joint, WOMAC, Harris Hip Score

\section{INTRODUCTION}

The incidence of femoroacetabular impingement (FAI) diagnosis becomes more and more frequent in the recent years. It is one of the hypothetical causes of hip joint degenerative disease development. The first changes in joint morphology are observed already in youngsters, while mostly physically active subjects, being in their third and fourth decade of life, attend the orthopedic doctor, seeking for medical help [1].

Femoroacetabular impingement may be divided into 3 types, taking into account the anatomical features of the acetabular impingement, resulting from abnormal abut-

Received: June 26, 2018. Accepted: August 282018.

Corresponding author: Andrzej Borowski, Medical University of Lodz, Orthopedics and Pediatrics Orthopedics Department, Pomorska 251, 90-001 Łódź, Poland (e-mail: aborowski@xl.wp.pl). 
ment of the anterolateral femoral head-neck junction. The first type, the so-called Pincer-type impingement, is characterized by the over-coverage of the femoral bone head by the acetabular rim extension. The second type is CAM impingement with aspherical head-neck junction in the proximal end of the femoral bone. In $86 \%$ of FAI cases, a mixed type is observed, with both CAM and Pincer features [1,2]. Effective treatment of femoroacetabular impingement slows down the progression of degenerative disease for younger subjects [2]. Osteochondroplasty after hip joint displacement has become a golden standard of surgical treatment of the femoroacetabular impingement, following a description of a surgical procedure by Ganz et al., taking into account the anatomy of vascularization of the proximal femoral bone [3].

However, in the recent years, arthroscopic techniques are more and more often indicated in FAI treatment [4]. The results of both techniques are equally good but the arthroscopic approach is associated with a smaller risk of complications and with the higher health-related Quality of Life (HRQOL) index [5]. There are no clearly defined guidelines in the current literature reports, concerning arthroscopic treatment of FAI in patients with degenerative changes of hip joints. Following current reports, the treatment outcomes are very good for patients without degenerative changes in the articular cartilage, while for patients with advanced degenerative disease, the outcomes are rather poor $[6,7]$. Several recent studies show that patients are able to return to work without restrictions after reaching maximal medical improvement at a minimum of 1-year following hip arthroscopy $[8,9]$.

The primary endpoints of the study were to assess the effectiveness of hip joint arthroscopy in the treatment of femoroacetabular impingement in patients with joint gap stenosis exceeding the assumed, hypothetical limit point of $3 \mathrm{~mm}$, and to determine how quickly post-operative patients were able to return to work and to physical activity.

\section{MATERIAL AND METHODS}

It was assumed that the $3 \mathrm{~mm}$ width of the joint gap was a hypothetical border point, regarding the indications to hip joint arthroscopy. The exclusion criteria included the patients with the joint gap $<2 \mathrm{~mm}$, as confirmed in radiological studies, as well as patients with dysplasia of hip joints or aseptic necrosis of femoral bone head in history or who had ever undergone surgical interventions at the region of their hip joints. Eventually, the prospective study involved 92 patients, operated during the years 2012-2014 by means of the arthroscopic technique for CAM-type femoroacetabular impingement (Figure 1). That study group included patients with hip joint gap of 2-3 mm, identified in the standardized X-ray examination in anteroposterior (AP) view (Figure 2).

The study participants included 23 female and 24 male individuals. The youngest patient was 37 years old, while the oldest one was 57 years old, which made the most effective period at work. The mean age of the patients was 43 years old. The control group included 45 patients with hip joint gap $>3 \mathrm{~mm}$. There were 6 females and 39 males. The youngest patient was 34 years old, while the oldest one was 48 years old. The mean age of the patients was 41 years old. The post-operative follow-up period of the patients after hip joint arthroscopy lasted at least 2 years (2-3 years). After that period, the patients were examined at the Orthopaedic Outpatient Clinic, where clinical studies were carried out.

Patients filled out the Harris Hip Score (HHS) questionnaire, which assessed pain, activity, deformation, and range of motion. The score had a maximum of 100 points, and the obtained results correspond to the results very good ( $>85$ points), good (70-84 points), sufficient (60-69 points) and bad ( $<60$ points). In addition, in the course of the last follow-up examination, the Western Ontario McMaster Universities Osteoarthritis Index (WOMAC) questionnaire was applied, allowing for an accurate evaluation of pain sensations in patients with degenerative dis- 


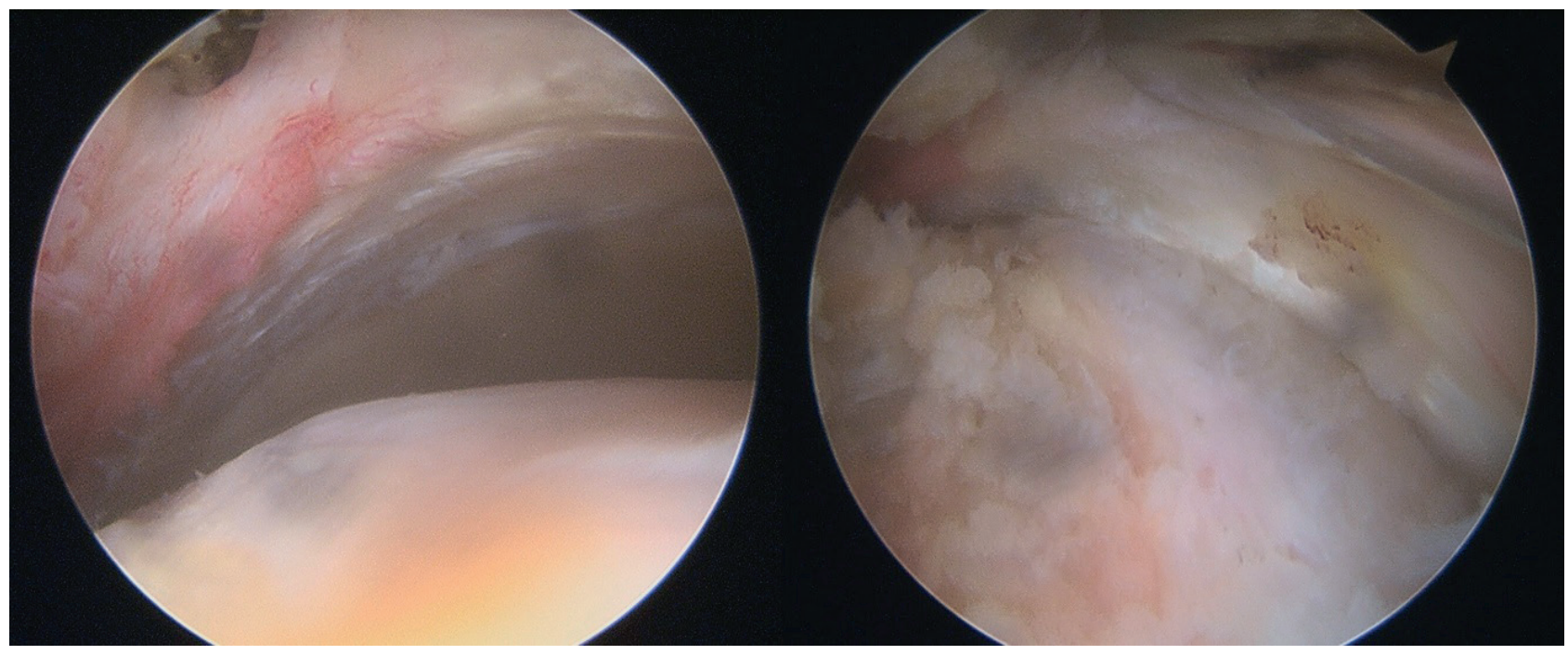

Figure 1. The arthroscopic view of hip joint with CAM femoroacetabular impingement a) partial/degenerative lesion of the labrum; b) the impact of the femoral bump leads to a disruption at the chondro-labral union

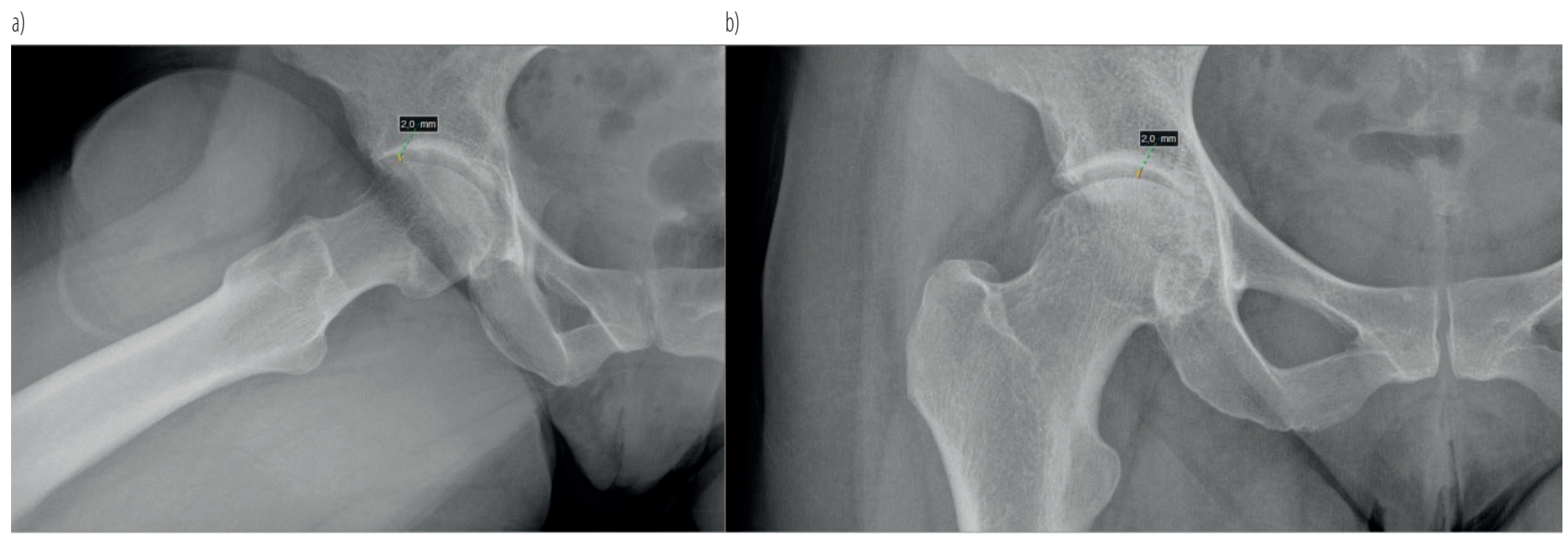

Figure 2. The radiology demonstrated a femoroacetabular impingement (FAI) with a significant CAM deformity and joint space narrowing on both a) axial view; b) AP view

ease of hip and knee joints. The questionnaire consisted of 24 questions, out of which, 5 questions evaluated pain intensity, 2 questions applied to joint stiffness and the remaining 17 questions targeted physical functions. The maximal score was 96 [10]. The patients were also enquired about the time period between surgery and ailment regression, enabling their return to physical activity at the level the same as before the operation. In addition, the patients with recurrent or persistent pain, were questioned about their view, regarding a potential repetition of the arthroscopic procedure as an alternative for total hip joint arthroplasty.

\section{RESULTS}

During at least 2 years of the post-operative follow-up, in the study group, pain sensations either recurred or did not regress in 37 patients after surgery, which accounted for $78.72 \%$ of the group. In the control group pain recurred in 12 patients, which accounted for $26.67 \%$ of the group. 
Despite the rather poor outcome of the therapy in the study group, 31 out of 37 asked patients, gave a positive answer to the proposal of repeated hip joint arthroscopy, if it were to have helped put off the decision of total hip joint arthroplasty.

The mean result of the WOMAC questionnaire before operation in the study and the control group was comparable. In the study group the result stood at 26.62 points, i.e., $27.73 \%$ of the maximal score, where the lowest result stood at 14 points and the highest one amounted to 44 points. In the control group the result stood at 29.51 points, i.e., $30.74 \%$, where the lowest result stood at 18 points and the highest amounted to 54 points.

The mean result after the operation varies in both groups. The mean result in the study group was 23.33 (24.3\% of total), in the control group it was 34.57 (36.01\% of total) during the follow-up examination after surgery. The lowest obtained result in the study group stood at 13 points $(13.5 \%$ of total), while the highest result stood at 39 points $(40.6 \%$ of total). The lowest obtained result in the control group was 17 (17.71\% of total) while the highest was $62(64.58 \%$ of total) (Table 1). In the study group the average HHS questionnaire before surgery gave the result of 67 points, while during the last check-up - it gave 66 points, in the control group before surgery the average HHS stood at 69 points, while during the last check-up - it stood at 83 points. All the patients after hip joint arthroscopy returned to normal physical activity within 12 weeks from operation, enabling their return to work. The mean period of return to full physical ability was 8 weeks in the study group and 3 weeks in the control group. Despite unsatisfactory pain relief, patients decided to return to work, due to their occupational position and for fear of losing the job due to long absenteeism.

\section{DISCUSSION}

The study demonstrated a strong correlation between joint gap width and the outcome of femoroacetabular impingement treatment by means of the arthroscopic approach in the hip joint. In the patients with joint gap $\leq 3 \mathrm{~mm}$, the result of treatment was unsatisfactory in $78.72 \%$ of the operated cases. It was also demonstrated in earlier studies. Byrd et al. [11], in a report from their

Table 1. The score of the Western Ontario McMaster Universities Osteoarthritis Index (WOMAC) questionnaire [10] in the study and control group

\begin{tabular}{lcc}
\hline & Variable & Score \\
\cline { 2 - 3 } & before surgery & after surgery \\
\hline Pain $(\mathrm{M})$ & & \\
$\quad$ study group & 7.63 & 6.85 \\
$\quad$ control group & 7.82 & 10.04 \\
Stiffness (M) & & \\
$\quad$ study group & 1.91 & 1.53 \\
$\quad$ control group & 2.67 & 3.29 \\
Physical functioning (M) & & \\
study group & 17.06 & 14.95 \\
$\quad$ control group & 19.02 & 21.24 \\
Total [n (\%)] & & \\
$\quad$ study group & $26.62(27.73)$ & $23.33(24.30)$ \\
$\quad$ control group & $29.51(30.74)$ & $34.57(36.01)$ \\
\hline
\end{tabular}


study of 220 hip joint arthroscopies, did emphasize the poor outcome of the applied therapy for patients with degenerative disease. The authors described 9 cases, in which hip joint arthroscopy had been carried out for patients with highly progressed degenerative changes of the articular cartilage and with reduced hip joint spaces, resulting from earlier lesions of the acetabular lip. Poor results of the treatment were observed for all the 9 patients. Larson et al. [12] drew similar conclusions after their assessment of 227 performed hip joint arthroscopies. In 58 cases, those were patients with joint gap, narrowed by more than $50 \%$, or with width $\leq 2 \mathrm{~mm}$. After one year of follow-up of that group of patients, neither pain sensations nor articular function disorders presented any regression in $52 \%$ of patients with radiologically confirmed degenerative changes.

Philliponn et al. [13] stated that total hip joint arthroplasty was 39 times more probably indicated for patients with hip joint gap $<2 \mathrm{~mm}$. Their study was carried out on a group of 122 patients after hip joint arthroscopy. After the average time period of 16 months, 10 patients did not show any improvement in their clinical condition, which indicated the necessity to perform the procedure of total arthroplasty.

Skendzel et al. [14] studied the probability of conversion to arthroplasty after hip joint arthroscopy. A group of 559 patients participated in the study and the mean follow-up period was 5 years. In $86 \%$ of the cases with hip joint gap stenosis to a level $<2 \mathrm{~mm}$, an early conversion to arthroplasty was decided after the average time period of 40 months, while the coefficient was only $16 \%$ in the group of patients with preserved joint gap space. Lynch et al. [15] stated that in the cases of hip joint gap stenosis vs. the opposite side or in presence of full thickness articular cartilage defects, either in the acetabulum or in the femoral bone head, a very careful qualification to arthroscopy was required.

In their study, Mella et al. [16] draw attention to the increasing possibilities of an accurate qualification of patients by diagnostic imaging, which is of key importance for the surgery outcome. A quick return to physical activity at the level, cor- responding to that from before the operation, enabling to undertake normal work again, was confirmed in the conclusions of Casartelli et al. [17], who analyzed the course of return to normal physical activity among sportsmen after surgery for femoroacetabular impingement. The study reported a tendency for a higher rate of return to sport in professional rather than in recreational athletes. The authors also stated that the baseline condition of the articular cartilage was significant for a quick return to full physical abilities. Whereas Dumb et al. [18] determined in their study the recovery time period for professional sportsmen to be within 12-20 weeks. On the contrary the surgical results for workers' compensations have been associated with inferior outcomes. It is believed that patients receiving workers' compensation have inferior outcomes across a range of clinical conditions. Lee et al. [8] found that the majority (69\%) of work's compensation-based patients are able to return to work without restrictions after reaching maximum medical improvement at a minimum of 1-year following hip arthroscopy.

In this study, no clinical improvement was noticed after hip arthroscopy, in terms of good results for professional athletes, in patients having $<3 \mathrm{~mm}$ hip joint gap, however all patients returned to pre-operation physical abilities. It was found that due to their statements, patients were interested in quick return to work because of occupied position sand prolonging absenteeism at work was not accepted for them. In patients with hip joint narrowing, hip arthroscopy turned out to be a waste of time and unnecessary exposure to complications.

\section{CONCLUSIONS}

Despite the little invasiveness, hip joint arthroscopy in patients with joint gap stenosis, brings about the far from satisfactory results. This procedure is not worth considering because of lack of potential advantages, such as significant pain relief or quick return of operated patients to physical activity and work. Patients return to work for reasons other than improvement of their medical conditions. 


\section{REFERENCES}

1. Beck M, Kalhor M, Leunig M, Ganz R. Hip morphology influences the pattern of damage to the acetabular cartilage: Femoroacetabular impingement as a cause of early osteoarthritis of the hip. J Bone Joint Surg Br. 2005;87(7):1012-8, https://doi.org/10.1302/0301-620X.87B7.15203.

2. Ganz R, Parvizi J, Beck M, Leuning M, Notzli H, Siebenrock KA. Femoroacetabular impingement: A cause for osteoarthritis of the hip. Clin Orthop Relat Res. 2003;417:112-20.

3. Ganz R, Gill TJ, Gautier E, Ganz K, Krugel N. Surgical dislocation of the adult hip a technique with full access to the femoral head and acetabulum without the risk of avascular necrosis. J Bone Joint Surg Br. 2001;83(8):1119-24, https:// doi.org/10.1302/0301-620X.83B8.0831119.

4. Bare AA, Guanche CA. Hip impingement: The role of arthroscopy. Orthopedics. 2005;28(3):266-73.

5. Nwachukwu BU, Rebolledo BJ, McCormick F, Rosas S, Harris JD, Kelly BT. Arthroscopic versus open treatment of femoroacetabular impingement: A systematic review of mediumto long-term outcomes. Am J Sports Med. 2016;44(4):10628, https://doi.org/10.1177/0363546515587719.

6. McCarthy JC, Lee JA. Arthroscopic intervention in early hip disease. Clin Orthop Relat Res. 2004;429:157-62.

7. Walton NP, Jahromi I, Lewis PL. Chondral degeneration and therapeutic hip arthroscopy. Int Orthop. 2004;28(6):354-6.

8. Lee S, Cvetanovich GL, Mascarenhas R, Wuerz TH, Mather RC, Bush-Joseph CA, et al. Ability to return to work without restrictions in workers compensation patients undergoing hip arthroscopy. J Hip Preserv Surg. 2017;4(1):30-8.

9. Dutton JR, Kusnezov NA, Lanzi JT, Garcia EJ, Pallis MP. The success of hip arthroscopy in an active duty population. Arthroscopy. 2016;32(11):2251-8, https://doi.org/10.1016/ j.arthro.2016.05.042.

10. Bellamy N, Buchanan WW, Goldsmith $\mathrm{CH}$, Campbell J, Stitt LW. Validation study of WOMAC: A health status instrument for measuring clinically important patient relevant outcomes to antirheumatic drug therapy in patients with osteoarthritis of the hip or knee. J Rheumatol. 1988;15(12):1833-40.

11. Byrd JW, Jones KS. Osteoarthritis caused by an inverted acetabular labrum: Radiographic diagnosis and arthroscopic treatment. Arthroscopy. 2002;18(7):741-7, https://doi.org/10. 1053/jars.2002.32837.

12. Larson CM, Giveans MR, Taylor M. Does arthroscopic FAI correction improve function with radiographic arthritis? Clin Orthop Relat Res. 2011;469(6):1667-76, https://doi. org/10.1007/s11999-010-1741-6.

13. Philippon MJ, Briggs KK, Yen YM, Kuppersmith DA. Outcomes following hip arthroscopy for femoroacetabular impingement with associated chondrolabral dysfunction: Minimum 2-year follow-up. J Bone Joint Surg Br. 2009;91(1): 16-23, https://doi.org/10.1302/0301-620X.91B1.21329.

14. Skendzel JG, Philippon MJ, Briggs KK, Goljan P. The effect of joint space on midterm outcomes after arthroscopic hip surgery for femoroacetabular impingement. Am J Sports Med. 2014;42(5):1127-33, https://doi. org/10.1177/0363546514526357.

15. Lynch TS, Terry MA, Bedi A, Kelly BT. Hip arthroscopic surgery: Patient evaluation, current indications, and outcomes. Am J Sports Med. 2013;41(5):1174-89, https://doi. org $/ 10.1177 / 0363546513476281$.

16. Mella C IEV, Nunez A, Paccot D, Diaz-Ledezma C. Hip arthroscopy and osteoarthritis: Where are the limits and indications? SICOT-J. 2015;1-9.

17. Casartelli NC, Leunig M, Maffiuletti NA, Bizzini M. Return to sport after hip surgery for femoroacetabular impingement: A systematic review. Br J Sports Med. 2015;49(12):819-24, https://doi.org/10.1136/bjsports-2014-094414.

18. Domb BG, Stake CE, Finch NA, Cramer TL. Return to sport after hip arthroscopy: Aggregate recommendations from high-volume hip arthroscopy centers. Orthopedics. 2014; 37(10):e902-5, https://doi.org/10.3928/01477447-20140924-57.

This work is available in Open Access model and licensed under a Creative Commons Attribution-NonCommercial 3.0 Poland License - http://creativecommons.org/ licenses/by-nc/3.0/pl/deed.en. 